\title{
An exploration of the experience of trainee integrative psychotherapists on therapeutic alliance in the light of their attachment style
}

\author{
Eleni Rizou, Vaitsa Giannouli \\ MSc Integrative Counselling and Psychotherapy, Mediterranean College \& Derby University, \\ Thessaloniki, Greece
}

\begin{abstract}
Therapeutic Relationship has been regarded as a profound element of the psychotherapeutic procedure and crucial for the outcome of therapy. Research evidence so far claims that both therapist's and client's personality can impact the Therapeutic Relationship. Based on the well-researched Attachment Theory there has been some research mostly focused on how clients' attachment patterns can affect the Alliance. Limited research, though, on how therapists experience the Relationship in relation with their Attachment Styles do exist. The current study investigates trainee therapists' experience of the Therapeutic Relationship in the light of their Attachment Style. A qualitative approach was used for this research to investigate in depth the experience of five trainee Integrative psychotherapists who were recruited to take part in semi-structured interviews. Interviews were transcribed and verbatim was divided into superordinate and subordinate themes and analyzed by Interpretative Phenomenological Analysis method.
\end{abstract}

Correspondence: Eleni Rizou, MSc Integrative Counselling and Psychotherapy, Mediterranean College \& Derby University, Thessaloniki, Greece.

E-mail: elenan.rizou@yahoo.com

Key words: Trainee; integrative psychotherapist; therapeutic alliance; attachment style.

Contributions: ER and VG jointly initiated the study and planned the research design. ER collected the data and wrote the first version of the paper. All the authors critically read and revised the final version of the manuscript.

Conflict of interest: The authors declare no conflict of interest.

Funding: None.

Availability of data and materials: All data and materials are available in the text.

Received for publication: 12 June 2020.

Revision received: 8 November 2020.

Accepted for publication: 19 November 2020 .

This work is licensed under a Creative Commons AttributionNonCommercial 4.0 International License (CC BY-NC 4.0).

CCopyright: the Author(s), 2020

Licensee PAGEPress, Italy

Health Psychology Research 2020; 8:9177

doi:10.4081/hpr.2020.9177
Four master themes were identified. Findings were then compared and discussed according to existing literature. All participants referred to the relevance of Attachment Theory in psychotherapy. They also agreed on the activation of their Attachment Styles during the therapeutic process. The securely attached therapist confirms previous studies on her capability to offer a secure base for her clients. On the other hand therapists with insecure Attachment Styles appeared sensitive in their collaboration mostly with insecure clients. Anxiously attached therapists proved to experience difficulty in the initial stages of the Therapeutic Relationship while the combination of avoidant therapist-avoidant client appeared to be the most demanding one, regarding the concept of trust and relationship ruptures. We suggest that the exploration of trainee therapists' Attachment Styles as well as the study of the Attachment Theory should be added to all Counseling and Psychotherapy curricula regardless the therapeutic orientation because of its contribution to forming positive Therapeutic Relationships.

\section{Introduction}

The present research is an Interpretative Phenomenological Analysis (Smith, Flowers and Larkin, 2009) and an exploration attempt of the impact of the Attachment Patterns of trainee Integrative psychotherapists on the highly recognized for its importance on psychotherapy outcome, Therapeutic Alliance (Horvath, Del Re, Flückiger, and Symonds, 2011) . Given its importance, it is no wonder that psychotherapy researchers have focused their interest on the variables contributing to a positive Alliance. Meta-analyses have offered strong support regarding the influence of the Alliance on therapy outcome, with a reported range of 0.22-0.26 on outcome-Alliance correlation (Horvath and Symonds, 1991; Martin, Garske \& Davies et al., 2000; Baldwin, Wampold \& Imal, 2007). The formation of a strong Therapeutic Alliance, though, is not a one-way process, since it is based both on clients and therapists quality (Black, Hardy, Turpin \& Parry, 2005). Thus, both parts of the dyad, their characteristics and influence have been studied for their impact on the Alliance research (Beutler, Machado \& Allstetter, 1994).

From Bowlby, who had characteristically referred to the Therapeutic Relationship as an "Attachment Relationship" (Bowlby, 1988) to recent researchers, Attachment Theory have been regularly used as an investigation framework for the exploration of Therapeutic Relationship because of its great influence on the way psychotherapy is demonstrated (Levy, Ellison, Scott \& Bernecker, 2011). Moreover, its strong theoretical background and its vast application on clinical practice provide with a relevant base when considering the investigation of the between client and therapist Alliance (Obegi, 2008).

Reviewing literature, there is a clear focus on clients' Attachment Style and its role in the Therapeutic Alliance (Daniel, 
2006; Smith, Msetfi, \& Golding 2010; Diener \& Monroe, 2011) with consistent finding suggesting that securely attached clients are better able to form positive Alliances (Mikulincer and Shaver, 2007).

On the other hand, there has been only limited research until 2003 on the attachment patterns of psychotherapists and the role of the therapist as an attachment figure (Parish \& Eagle, 2003). Just the year before an American study between 50 training therapists' and their supervisors had found no correlation between the therapists' Attachment Style and the overall therapeutic Alliance (Ligiero \& Gelso, 2002). Of the same results was one later study conducted on 59 dyads between Canadian trainee counselors and their clients (Romano, Fitzpatrick and Janzen, 2008). Therapist's attachment security was found not to be related to the development of the Therapeutic Alliance neither in two German studies (Dinger, Strack, Sachsse \& Schauenburg, 2009; Schauenburg et al., 2010).

In other studies, though, it was reported that therapists' Attachment Style can be as important as those of clients' (Ackerman \& Hilsenroth, 2003; Black et al., 2005; Bruck, Winston, Aderholt, \& Muran 2006; Mikulincer, Shaver and Berant, 2013; Marmarosh 2015 ) with therapists' characteristics reported to probably account for up to $8 \%$ of the variance in the therapeutic outcome (Kim, Wampold \& Bolt, 2006).

Although attachment system has been regarded of a central role in achieving interpersonal relationships and the Therapeutic Alliance (Taylor, Rietzschel, Danquah \& Berry, 2015) today only a small number of relevant studies have been conducted focusing on the role the Attachment Style of a therapist plays on the Therapeutic Alliance. Such studies suggest that therapist's attachment security can seriously affect the Therapeutic Relationship and therefore the outcome of the therapy as a whole (Black et al., 2005; Mikulincer et al., 2013; Gerhardt, 2015; Marmarosh, 2015).

The majority of the research, though, employed the quantitative rather than the qualitative paradigm to measure the improvement of Alliance during the therapy or the perceptions of clients and therapists on the Alliance or session evaluation regarding the Alliance (Dunkle \& Friedlander, 1996; Ligiero \& and Gelso, 2002; Mohr, Gelso \& Hill, 2005; Romano et al., 2008; Sauer, Lopez, \& Gormley, 2003). Consequently, studies so far have been less focused on the way therapists deal with their attachment behavior during therapy and may lack the depth of therapists' experience of the way they carry their Attachment Style in their relationship with their clients. To the best of the researcher's knowledge, there have been only two qualitative studies conducted by Mallinckrodt, Daly and Wang, (2008) and Daly and Mallinckrodt (2009). Both studies, though, used grounded theory (Charmaz, 2006; Fassinger, 2005; Strauss \& Corbin, 1998) in order to identify an inclusive theoretical model that could describe the approaching methods adopted by experienced therapists while working with clients of different Attachment Styles.

A therapist's early attachment experiences are likely to have an influence on the Therapeutic Alliance (Daniel, 2006). The relatively small number of research appearing in literature search investigated the attachment patterns of a varied sample of professionals such us clinical case managers, carers, counselors, psychotherapist of different orientations and psychologists always under the quantitative approach (Daniel, 2006). The influence of therapists' early attachment experiences on clinical practice emerged in only two qualitative studies under IPA methodology carried out by Rizq and Target (2008; 2010). Those researchers, though, investigated the topic mostly under the reflective perspectives personal therapy offers when engaged by counselors. Moreover, no studies were found that addressed this issue in light of the work of Integrative psychotherapists who beyond other approaches apply Attachment Theory as an assessment or treatment tool with their clients.

Accordingly, the main goal of the present study was to investigate the perceptions of trainee therapists on both Attachment and the Alliance through the qualitative paradigm because of its utility in providing deep and novel perspectives on unexplored or complex areas (Richardson, 1996). This research is worthwhile because it aims to provide the literature with additional findings on a rather unexplored areas but crucial for the outcome of the therapy, by exploring in depth the experience of a unique sample of trainee Integrative psychotherapists who haven't been explored under this topic before. Last but not least, the findings can provide novice psychotherapists with useful introspections on relationship challenges they might come across during their internship.

\section{Aim and Objectives}

This study was set out with the aim to explore in depth how trainee Integrative psychotherapists experience the impact of their Attachment Style on the so-called Therapeutic Alliance with their clients.

The researcher objectives were to explore the way Attachment Theory is applied in Theoretical Integrative Psychotherapy as well as the self-awareness of therapists who apply the Attachment Theory on their own Attachment Style. Moreover, it is an investigation attempt on therapists' experience regarding the activation of their Attachment bond in different stages of therapy and on experienced challenges when working with clients of different Attachment Styles. Last but not least, the total impact of therapists' Attachment Style on the Therapeutic Alliance is to be discussed during the interviews in order to gain a better understanding on this subject, which unlike its importance lacks research findings.

\section{Literature review}

An extensive literature search was carried out to key background context of Attachment Theory and Therapeutic Relationship in order to orient readers to important issues that may arise during the analysis of the interviews.

\section{The Therapeutic Alliance}

A key term of the subject of this study is "Therapeutic Alliance" which was also defined as the cooperative and meaningful way of work between client and therapist (Hatcher and Barends, 2006). The Alliance is based on therapists' ability to collaborate with the client by demonstrating genuineness and empathy and being emotionally attuned with their clients (Geller and Greenberg, 2002). The term was generated in the early years of psychoanalysis (Zetzel, 1956; Freud, 1958; Greenson, 1967) when Freud referred to the Alliance as the "friendly affectionate feeling" (Freud, 1958). The Alliance soon attracted the interest of researchers of different schools, like Carl Rogers from the humanistic approach who conceptualized Therapeutic Relationship through the core components of empathy, congruence and unconditional positive regard (Rogers, 1957). With numerous research regarding its importance for psychotherapy (Orlinsky, Ronnestad and Willutski, 2004), Therapeutic Alliance is now regarded as crucial for the therapeutic outcome by the majority of psychotherapeutic approaches(Johansson \& Eklund, 2003; 
Kirsch \& Tate, 2006; Catty, Winfield \& Clement, 2007), while for some more crucial than approaches themselves (Stiles, Barkham, Twigg, Mellor-Clark, \& Cooper 2006; Ross, 2006; Haugh \& Paul 2008). The emotional bond between a therapist and a client has been described in literature as one of the basic elements of psychotherapy (Bordin, 1979; Imel, Hubbard, Rutter \& Simon, 2013 ) and has been regarded among its four common factors with a $30 \%$ rate to predict positive therapeutic outcomes (Duncan, Hubble, Miller, \& Wampold, 2009).

\section{The Alliance through Process of Change}

For Theoretical Integration, the purpose of the Therapeutic Relationship is to facilitate an effective change of the dysfunctional behavior of the client through specific stages and levels (Prochaska $\&$ DiClemente, 2005). Therapeutic change takes place within the relational environment between therapists and clients while therapists ability to provide such a safe environment is what really facilitates change (Geller \& Porges, 2014). Ross's literature review confirmed that therapeutic change is associated with the quality of the therapeutic Alliance that goes beyond therapeutic approaches (Ross, 2006). In fact, the process of change has been regarded as the common ground where the r elationship between a therapist and a client is based on (Prochaska and DiClemente, 2005) and a complementary procedure through clients' and therapists' interactions (Duncan et al., 2009).

In particular, clients are described as "self-changers" and therapists as change experts whose role is to facilitate change through a strong relationship (Prochaska and DiClemente, 2005). The Therapeutic Relationship, in that case, can be better described as a dynamic process that varies depending on the stage of change. In pre-contemplation stage the therapist takes an advisory or caring role (DiClemente et al., 1991) while in the long-lasting contemplation stage the therapist takes up the role of a Socratic like teacher to explicit client's concerns towards change. At this stage, it is important that the therapist exhibits both patience and support before client's fears. Working with clients at the demanding stage of the action the Therapeutic Relationship becomes a formal teaching relationship while the therapist who can usually be seen as an expert should be aware of his client's to rely on a stable figure and offer himself as such while encouraging client's self-confidence at the same time. As therapy reaches its final stage, that of maintenance, the consulting role of the therapist becomes occasional and Therapeutic Relationship comes to its end (Prochaska and DiClemente, 2005).

\section{Attachment Theory}

The present research applies Attachment Theory to the perception of trainee Integrative psychotherapists with a focus on the exploration of the way therapists experience their own Attachment Styles during therapy.

The father of Attachment Theory, John Bowlby, a British psychoanalyst and psychiatrist, was the first to focus his research interest in the effects of early experience on children development of the last century. Through his study, Bowlby discussed the negative effects of young children separated from their safe family environment, while also proposing possible preventive measures (Bowlby, 1979). According to his findings, early interactions with caregivers were speculated to urge the development of mental representations of the self in relation to significant others that can predict and interpret ones future interpersonal relations (Bowlby, 1977). Consequently, a correlation between early experience and personality seemed obvious to Bowlby who suggested that individuals' behavior is ruled by their tendency to form an attachment relationship with important others (Bowlby, 1988).

Bowlby's Theory of Attachment was expanded and provided by further empirical support by Mary Ainsworth (Wallin, 2015) in a seminal study on infants brief separation from their caregivers, known as the 'strange situation' (Sroufe \& Siegel, 2011). Their laboratory-based observations showed different types of response to separation, which derived from different working models and distress regulation patterns (Ainsworth, Blehar, Waters \& Wall 1978). Thus, three dominant styles of attachment were described: secure, anxious and avoidant (Levy et al, 2011) with studies to suggest the quality rather than the quantity of care (Ainsworth et al., 1978) as well as the caregiver's availability and sensitivity to infants distress (Weinfield, Sroufe, Egeland, \& Carlson, 1999) as being catalytic on the formulation of an infant's Attachment Style. One more Attachment style, the disorganized Attachment Style, was later described by Mary Main (Main \& Solomon, 1986, 1990), who expanded the concept of Attachment Theory in Adult life (Wallin, 2015) and also contributed with his work on the connection between individuals Attachment Styles and internal working models to the Adult Attachment Interview (Johnson \& Whiffen, 2003). For a comprehensive review of Attachment Theory, one can refer to the Handbook of Attachment by Cassidy and Shaver (2008).

\section{Attachment Style of the Therapist}

Therapeutic Relationship mirrors base elements of an Attachment Relationship with many authors to support the parallelism between the two conditions (Bowlby, 1988; Epstein, 1995; Parish, 1999; Holmes, 2001; Parish \& Eagle, 2003; Daniel, 2006; Collins, 2007; Wallin, 2007; Mallinckrodt, 2010). Bowlby was the first to conceptualize the therapist as an attachment figure (as cited in Wallin, 2015) by comparing the role of the therapist with that of a responsive caregiver's who offers the infant with a secure base to explore the world. He referred to the importance of a therapist's behavior towards their client and the need for them to be always alert of the way they contribute to the relationship, a contribution that among others can also reflect their childhood experience (Bowlby, 1988). Another weighty evidence of the importance of the therapists history in the understanding of the Therapeutic Relationship (Wallin, 2007) can be found in early attempts of defining the Therapeutic Alliance and the term 'co-constructors' to have been chosen to describe the role of client and therapist in it (Smith et al., 2010).

Although few will argue with the importance of therapists' personality for the therapeutic outcome, until 2003 there is a dearth of empirical research focused either on the role of the therapist as an attachment figure or on the impact of the therapist's attachment style on the therapeutic Alliance (Parish \& Eagle, 2003).

Since then, researchers with an interest in the implication of the Attachment Theory in psychotherapy, having realized the literature gap, conducted some relevant research with mixed results. Marmarosh more recently described conclusions about the role of therapists' Attachment Style on the therapeutic process as rather ambiguous (Marmarosh, Kivlighan, Bieri, Schutt, Barone, \& Choi, 2014).

Success on Therapeutic Alliance can be predicted by thera- 
pist's personality and style as well as his psychological attendance (Bankart, 1997). Dunkle and Friedlander (1996) found that therapists' Attachment Styles define their ability to treat a client in an empathic way.

Therapists' primary relational experiences shape their Internal Working Models and thus the way they relate to clients in the therapeutic procedure (Marmarosh, 2015). According to Mikulincer et al.'s (2013) study, which aimed to explore whether therapists Attachment Styles influence the therapeutic Alliance, securely attached therapists are more likely to form a strong therapeutic Alliance; they appear more capable in taking on the caregiver's role even when working with demanding clients and are able to better cope with distressed ones or those who demonstrate high resistance during therapy. A therapist's sense of security is relevant to his capacity to provide client with a secure and sound place and therefore with a positive Therapeutic Alliance (Bachelor, 2013; Mikulincer et al., 2013). On the other hand, insecure therapists have a difficulty to successfully handle difficult clients as well as their own anxiety before the challenges of the Therapeutic Relationship.

Under the strong belief that the Therapeutic Alliance greatly determines successful psychotherapy, Dinger et al. (2009) included therapists' Attachment Styles in correlation with clients' interpersonal difficulties to study the influence of both on the therapeutic Alliance. Researchers reported a positive Alliance between secure psychotherapists and their clients. However, a large number of psychotherapists who were classified as insecurely attached during the study were also found able to meaningfully relate with their clients. Eventually, it was concluded that neither Attachment Styles of therapists' has a negative impact on the formulating of the Therapeutic Alliance. Similarly, in Marmarosh study a number of researchers appeared to suggest that despite the activation of the therapist's Attachment Style in the therapeutic dyad, its impact on the therapeutic Alliance is relatively smaller than the Attachment Style of the client (Black et al.; Dozier et al.; Dunkle \& Friedlander; Mohr, Gelso \& Hill; Rubino et al.; Sauer et al.; as cited in Marmarosh et al., 2014).

Black et al., (2005) suggested that the quality of Alliance, especially during the initial stage of therapy, is catalytic for its outcomes. They referred to the lack of relevant research on therapists Attachment Styles and stressed out that the ability of a therapist to create sound relationships are of the same importance as clients' qualities. Black et al. (2005) started with the hypothesis that securely attached therapists would prove better at forming strong Alliances than insecurely attached ones. Their study was based absolutely on self-reported Attachment Styles of the therapists, which, together with their orientation, could affect Alliance quality and emerged challenges during therapy. Their findings came to confirm that hypothesis: Therapists of the secure Attachment Style were reported forming stronger Alliances with their clients while the therapists of insecure Attachment Styles were found with less positive Alliances especially with insecurely attached clients. Moreover, a lack of depth in middle sessions of therapy between avoidant therapists and anxious clients was detected when the therapeutic Alliance had not been properly established at first place (Romano et al., 2008).

Research has also shown that anxiously attached therapists were rated by clients to perform under a less empathic and caring way during therapy (Rubino, Barker, Roth, \& Fearon, 2000) and facilitated a lower Alliance quality (Dinger et al., 2009)

Ligiero and Gelso (2002) focused their study on the way the Alliance is influenced by both client and therapist's personality claiming the importance of understanding the Therapeutic Alliance through therapist's Attachment Style and countertransference behavior. According to the research finding, even the Attachment Style of therapists can influence their interpersonal relationships, no evidence was found that can be also reflected and impacts the relationship with their clients or countertransference procedure. According to a later research, though, fearful or dismissing attached therapists were found to perform under negative countertransference when working with anxious clients (Mohr et al., 2005). Similarly to Bowlby, who stressed the importance of therapists' awareness towards their Attachment Style and the need of continuous reflection on how they offer themselves to their clients, Holmes (2010) highlighted the need for effective therapists to be aware of their own Attachment Style. The year before, a study by Rizq and Target (2008) explored the way personal therapy can address in this direction. According to the findings, personal therapy focused on early attachment experience of therapist proved to enhance to therapist reflective abilities. In the same direction, training curricula were also suggested to facilitate anxiously attached therapist to strengthen their abilities to work with all type of clients (Romano et al., 2008). Those same dyads of Rizq and Target in a later study were not able to further prove their former findings. In fact, second research showed mixed results and suggested that personal therapy can even lead to unhelpful intrapersonal conflicts and preoccupation regarding a therapist's capacities in clinical practice (Rizq \& Target, 2010) An explanation to this might be that when therapists become aware of their susceptibility towards specific Attachment Styles can raise their defense rather than lower it towards particular clients (Dozier, Cue \& Barnett as cited in Bachelor, Meunier, Laverdiére, \& Gamache, 2010).

Bucci, Seymour-Hyde, Harris, and Berry (2016) suggested that therapists' acknowledgement on their own attachment style and therefore their childhood experience is substantial in case they want to offer themselves as caregivers and form strong therapeutic Alliances. Above claim was also embraced by Daniels (as cited in Marmarosh et al., 2014) who stressed that therapists who feel weak before their experiences and are unable to deal previous insecure bonds might fail in building positive Therapeutic Alliances.

\section{Client's Attachment Style and therapy}

According to recent research, a client's relational background can affect the relationship and the way a therapist's role as an attachment figure is finally perceived (Cortina, 2013). Assessment of a client's Attachment Style has been, consequently, found crucial for the outcome of therapy, since both client's and therapist's Attachment Styles have an impact on responses of both parts and therefore on the quality of the Therapeutic Relationship as well as the whole therapeutic procedure (Levy et al., 2011).

Furthermore, the ability of a therapist to take insights about a client's attachment style could prove helpful with predicting possible challenges that might arise while building a Therapeutic Relationship and understanding the way clients respond to these challenges, to therapeutic interventions and goals and to their treatment in total (Levy et al., 2011).

To start with, securely attached clients were reported with better therapeutic outcomes in comparison to the insecure ones by a relevant meta-analysis (Levy et al., 2011). They better engage to psychotherapy, are more receptive to disclose themselves, more active and capable of recalling, integrating or interpreting their past (Romano et al., 2008). Clients with a secure Attachment Style often have a positive depiction of the therapist and perceive them 
as emotionally available and attuned (Bachelor et al., 2010).

On the other hand, research findings indicated that therapists should be more patient when forming a secure Therapeutic Alliance with insecurely attached clients, since they tend to lack the ability to establish strong realtionships, (Diener \& Monroe, 2011). Moreover, higher challenges are expected by therapists when working with insecure clients (Geller \& Farber, 2015).

Over-focused on attracting security and care from their relationships, clients with an anxious style of attachment usually suffer from a number of psychologically based symptoms and a problematic regulation of their emotions, which can vary from anxiety to depression (Bachelor et al., 2010; Connors, 2011). They tent to easily engage to therapy at first place and can be regarded as easy to treat by therapists (Levy et al., 2011) as they cooperate well; positive outcomes during therapy, though, are less expected (Levy et al., 2011). Anxious clients respond better to longer treatment and supportive therapists (Levy et al., 2011). Emotional regulation is also recommended for anxious attached clients (Levy et al., 2011), with cognitive therapy to better suit such clients because of their emotion deactivating role (Daniel, 2006; Purnell, 2010).

As far as clients that better match the avoidant Attachment Style are concerned, they tend to avoid intimacy and to have difficulty in relying on the third party. Consequently, they are less likely to seek for helping relationships, even when in hard times (Connors, 2011). A therapist might need to take up a more engaging role with clients who demonstrate an avoidant style of attachment (Levy et al., 2011) while emotionally oriented therapies, like psychodynamic therapy, are a more appropriate choice (Daniel, 2006; Purnell, 2010).

Last but not least, in cases of traumatized clients, who are better described as disorganized, therapists need to provide them with a supportive and trustworthy environment to gradually facilitate the regulation of their defensive mechanisms and metallization of overwhelming emotional conditions (Cortina, 2013).

Geller and Farber (2015) summarized possible challenges a therapist may anticipate while trying a positive Therapeutic Alliance with insecurely attached clients. First of all, they referred to the connection of the dyad, possible ruptures in the relationship or lack of empathic attunement and disconnections. Then they reported alternations to a way a therapist use self-disclosure or show compassion before the client. Boundaries matters in relation to the cancellation policy, therapy fees, punctuality and duration of therapy were also mentioned as constructive issues a therapist should take into account when working with insecure clients. At any case, a therapist should be flexible to adopt an attitude that incommodes clients; a Bowlby's assertion (1988) that found further support by modern models that suggest the "regulation of therapeutic distance" as the key factor to therapeutic change (Daly \& Mallinckrodt, 2009).

\section{Methodology and Methods}

The current study was carried under the qualitative paradigm, because it aims to explore a complex human experienced process (Ponterotto, 2005), the process of therapy and the Therapeutic Alliance in particular, and to access the unique experience of the participants which could not be captured via quantitative tools (Giannouli, Tegos, Zilakaki, \& Tsolaki, 2019; Giannouli, 2020; Morrow, 2007). An additional reason for choosing qualitative methodology as best suited for this research topic is that according to relevant literature review the majority of so far conducted research has been under the quantitative paradigm and has provided with mixed results about the influence of therapists' Attachment Styles on the Therapeutic Alliance.

IPA's dynamic process (Smith, 1996) was preferred for this study because of its creativity which matches the researchers' character as well as its deep insight of the emotional life of individuals that facilitates the investigation of complex issues through the analysis of emerged contradictions and similarities (Smith, Flowers \& Larkin, 2013). For phenomenology, subjectivity, experience, and process-directed human function is of great importance (Bartlett, 1998). Accordingly, by focusing on the lived experience of trainee psychotherapists this study will deepen the understanding of the effect of their Attachment Styles on the experience of the Therapeutic Alliance.

\section{Sampling}

Purposive sampling was employed to ensure that participants hold the relevant and experience this study aims to investigate (Langdridge, 2007). The voluntary recruitment of participants was purposive so as a homogeneous sample is found something that is very important for the ideographic nature of IPA methodology (Smith \& Osborn, 2003). Accordingly, trainee psychotherapists who implement the Integrative approach were recruited. A small sample of five participants was preferred, so as full attention is given to each case (Pietkiewicz and Smith, 2012; Levitt, 2015) since IPA's aim is a detailed, in-depth exploration of the individual experience, until data saturation is reached (Smith et al., 2009;)

\section{Recruitment}

Recruitment of the participants took place in November 2018. Participants were recruited from MSc Psychotherapy Integrative Psychotherapy programs in Thessaloniki, Greece so that a homogenous sample would be reassured (Smith et al., 2009).

Demographic details of final interviewees, their age, gender, theoretical orientation, hours of the internship were obtained in advance of each interview and can be found in Table 1 .

\section{Ethical considerations}

Prior to research ethical approval was obtained from the Research Ethics Committee of the University of Derby. The study was found to comply with the Policy and Code of Practice on Research Ethics (Derby.ac.uk, 2018) of the aforementioned university, the Data Protection Act 1998 (Legislation.gov.uk, 2018) and the Ethical guidelines for researching counseling and psychotherapy of British Association for Counselling and Psychotherapy (2004).

\section{Data collection}

The researcher interviewed participants during individual faceto-face interviews that took place in an office within their placements premises. The duration of each interview was approximately

Table 1. Participants characteristics.

\begin{tabular}{lcccc} 
Pseudonym & Age & Gender & $\begin{array}{c}\text { Theoretical } \\
\text { orientation }\end{array}$ & $\begin{array}{c}\text { Hours } \\
\text { of internship }\end{array}$ \\
Peter & 35 & Male & Integrative & 350 \\
Alex & 30 & Male & Integrative & 1000 \\
\hline Anna & 39 & Female & Integrative & 350 \\
Maria & 25 & Female & Integrative & 350 \\
\hline Sofia & 28 & Female & Integrative & 400 \\
\hline
\end{tabular}


45 minutes, which is adequate time for that type of interview (DiCicco-Bloom \& Crabtree, 2006). A widely used in qualitative research semi-structured interview model (Edwards \& Holland, 2013) was used for collecting maximum data as the research topic was already known (Smith, 2004; McLeod, 2003). In this direction, an interview schedule was in advanced formed according to the objectives of the study. Open-ended preset questions were initially developed and pilot tested during a pilot interview, while follow up questions, tailored to interviewees' replies, were improved to facilitate naturally fluid conversation (Creswell, 2007). Moreover, this non-directive interview schedule contributed to the so important for the IPA free and in-depth narration and description of the participants' experience on the theme (Smith, 2003; Clarke $\&$ Braun, 2016). Interview data were captured by audiotaping, with the participants' permission, because of its accuracy (Fielding, 1993; Holloway \& Wheeler, 1996) and suitability for additional analysis (Sandelowski, 1994) by generating a verbatim transcript.

\section{Data analysis}

Data were conducted through Smith's six-step model (Smith et al., 2013) which was applied separately for each participant (Table 2).

\section{Results}

Results are focused on the four major themes that emerged after the analysis of the data: i) The application of the Attachment Theory in Integrative psychotherapy; ii) The therapist's Attachment Style and the Therapeutic Relationship; iii) The therapist and client's Attachment Styles, interactions and the Therapeutic Relationship; iv) The total impact of the Therapist's Attachment Style on the Therapeutic Relationship and outcome psychotherapy.

Figure 1 depicts the four major themes and their subthemes emerged during the interview.

\section{A quick ideographic overview}

A short ideographic presentation of the interviewees is demonstrated in Table 3.

Table 2. Data analysis process.

\begin{tabular}{|c|c|}
\hline Steps & Actions \\
\hline $1^{\text {st }}$ Step & Repeatedly Reading \\
\hline $2^{\text {nd }}$ Step & Initial Noting \\
\hline 3rd Step & Coding of Emerged Themes \\
\hline $4^{\text {th }}$ Step & Identification of Recurrent Themes \\
\hline $5^{\text {th }}$ Step & Continue with next Transcript \\
\hline $6^{\text {th }}$ Step & $\begin{array}{l}\text { Identification of Patterns Across Interviews- } \\
\text { Development of Fixed Superordinate Themes }\end{array}$ \\
\hline
\end{tabular}

\section{Discussion}

\section{The application of the Theory of Attachment Theory in Integrative psychotherapy}

This question explored the relevance and application of the Attachment Theory in Integrative psychotherapy. The results of the study shows a great relevance of the Theory of Attachment for Integrative psychotherapeutic practice with all the participants to describe the Theory as a useful and important tool something that coincides with Bowlby's early suggestion on the utility of the Theory on specifying technique in therapy, as well as later suggested application of the Attachment Theory which recently attracted further research interest (Mikulincer et al., 2013) and underlined the strong correlation between Attachment Theory and psychotherapy (Levy et al., 2010). Individuals early experiences and their influence on the way they respond to the Therapeutic Relationship (Harris, 2004) was mentioned by Anna while an association between traumatic attachment experience in clients' early years
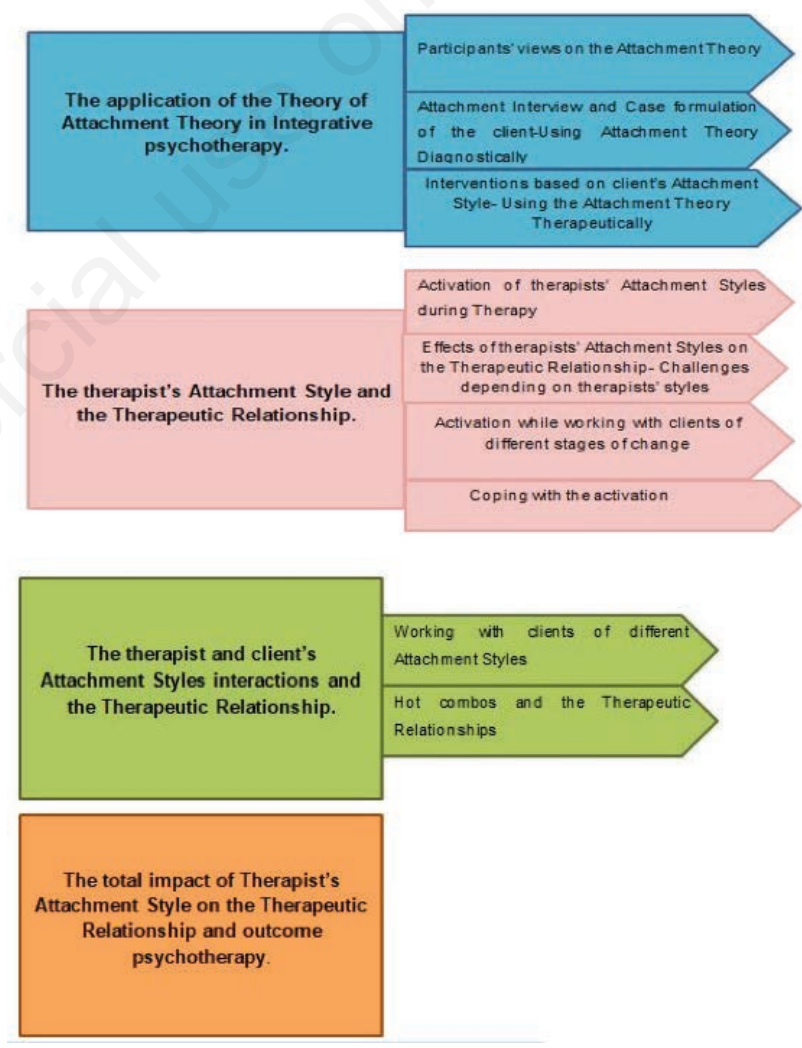

Figure 1. Major themes and subthemes emerged during the interview.

Table 3. Ideographic presentation of the interviewees.

\begin{tabular}{lcc} 
Therapist's pseudonym & Therapist's attachment style & Way of assessment \\
Alex & Insecure-Avoidant & Self-referred \\
Anna & Insecure-Ambivalent & Self-referred \\
\hline Maria & Insecure-Ambivalent & Self-referred \\
Peter & Insecure-Avoidant & Adult Attachment Questionnaire \\
Sofia & Secure & Self-referred
\end{tabular}


and dysfunctional patterns regarding relational behavior were described by three participants during their interviews, just like this was suggested by Cassidy, Jones, and Shaver (2013). All participants, finally, agreed on the influence of early experience management on their clients' adult life (McCluskey, 2005). Alex, who also recognized the Attachment Theory as a useful tool in clinical practice, mostly reflected on his experience as a trainee psychotherapist by stressing out the importance of the Theory for novice therapists, a suggestion that could get further research interest since, to the researcher's knowledge, there is a lack of relevant study so far.

\section{Using the Attachment Theory Diagnostically}

All participants recalled the use of the Attachment Theory as an assessing tool and agreed on the crucial role of the assessment of a client's attachment style for the Therapeutic Relationship as well as the outcome of therapy (Levy et al., 2011).

They stressed its importance and described the way they apply the Adult Attachment Interview (Main, Kaplan and Cassidy, 1985) at the initial stages of therapy to case formulate their clients. Alex and Maria pointed out how difficult and time demanding the whole process can be when they have to deal with insecurely attached clients, who according to relevant research and unlike to secure ones have a difficulty to engage to psychotherapy, are not receptive to disclose themselves, are incapable of recalling, integrating or interpreting their past (Romano et al., 2008). Emotional disturbance while searching the past of traumatized clients is another challenge mentioned by Alex that coincides with Cortina's (2013) findings of the defensive mechanisms and overwhelming emotional condition a therapist should overcome when interviewing and working with disorganized clients.

\section{Using the Attachment Theory Therapeutically}

Clinical application of Attachment Theory was initially introduced by its generator, Bowlby, who referred to the utility of the theory on specifying technique in therapy (Bowlby, 1977). Information obtained from the interviewees reflected that four out of the five participants apply the Attachment Theory in the form of intervention to secure a positive outcome for their clients, as suggested by Bowlby (1988). Four out of five participants reflected on their need to offer themselves as a secure base for their clients, especially for those who did not have the chance to grow up in a secure environment. The envision of the therapists as a "safe haven" (Bowlby, 1988) where a client can deeper disclose himself (Bachelor, 2013) and safely experience change (Romano et al., 2008) or explore and reflect distressing past experience and memories on (Bachelor, 2013; Mikulincer et al., 2013) has attracted much research interest so far. Eventually, a therapist can operate as an alternative to an insecure caregiving experience (Guina, 2016). Moreover, the Therapeutic Relationship was described to mirror base elements of an attachment relationship according to participants' experience, while many authors also support the parallelism between the two conditions (Bowlby, 1988; Epstein, 1995; Parish, 1999; Holmes, 2001; Parish \& Eagle, 2003; Daniel, 2006; Collins, 2007; Wallin, 2007; Mallinckrodt, 2010, Fisher, 2014, Lilliengren, Sandell, Falkenstrom, Mothlander, \& Werbart 2015). Another intervention mentioned by interviewees was the use of Attachment Theory for psychoeducational reasons. Maria and Peter characteristically described how they use Attachment Theory and assumptions on the Attachment style of their clients to educate them on their internal working models by "giving it back to them". While Alex trains his clients on how their IWMs "give space to here and now". Bowlby also suggested the observation of clients IWMs and referred to the role of a therapist to bring them to conscious during therapy (1988).

\section{The therapist's Attachment Style and the Therapeutic Relationship}

This section explores the relation between the activation of a therapist's attachment style and the Therapeutic Relationship while research findings, so far, regarding the relationship between therapists' Attachment Styles and the therapeutic procedure have been according to Marmarosh et al. (2014) rather vague.

\section{Activation of therapists'Attachment Styles during Therapy}

In a study conducted by Ligiero and Gelso (2002) a therapist's attachment style wasn't always activated during the treatment process. In this study, only one out of five therapists, Sofia, who reported herself as securely attached, reflected no experience regarding the activation of her Attachment Style during therapy. She referred to her attachment style as being an unconscious part of herself that just exists. Another participant, ambivalent attached Maria, stated that have experienced her anxious Attachment style being rarely activated, exclusively when working with demanding or male clients while this activation is more common in her personal relationships, something that was also highlighted by research (Ligiero \& Gelso, 2002). Subsequently, unlike existed research, four out of five participants of this study - all with insecure Attachment Styles - disclosed their experience regarding the activation of their Attachment Styles during therapy and discussed the impact of this activation on the Therapeutic Relationship by presenting examples of their work with specific clients.

\section{Effects of therapists' Attachment Styles on the Therapeutic Relationship. Challenges depending on therapists' styles}

The activation of the therapist's attachment style, although suggested by some research, is believed to have a lower impact on the Therapeutic Relationship than the client's attachment style (Black et al.; Dozier et al.; Dunkle \& Friedlander; Mohr, Gelso \& Hill; Rubino et al.; Sauer et al.; as cited in Marmarosh et al., 2014). All participants were asked about the effects of the activation of their personal Attachment Styles on the Therapeutic Relationship. Each unsecured Attached therapist reported negative effects of this activation on the rapport. The one secure attached therapist even denied any "activation" referred to the positive impacts of her secure existed attachment style.

Bowlby referred to the contribution of the therapist's personality, which reflects their primary experience, to the Therapeutic Relationship (1988). Similarly, Wallin attempted to understand the Alliance through the therapist's personal history. Eventually, a therapist's internal models, which are shaped under their primary relational experiences, can affect the capacity to relate to clients (Marmarosh, 2015). According to Mikulincer et al. (2013) secure attached therapists are more likely to form a positive therapeutic Alliance; they appear more capable in taking on the caregiver's role even when working with difficult clients and are able to better cope with distressed ones or those who demonstrate high resistance during therapy. Sofia, who has described herself as a securely attached therapist reflected similar experience; her clients' insecure attachment style cannot influence her work with them since she can offer herself as a stable base to build their relation on. Sofia also referred to her positive countertransference due to her secure attachment bond despite the ambiguous findings by existing studies; Dozier, Cue and Barnett (1994) claimed that securely attached psychotherapists are capable of better reflect on their feelings 
towards clients, while no evidence was found in a later study that a therapist's attachment style can be also reflected on countertransference procedure (Ligiero \& Gelso, 2002).

On the other hand, insecure therapists were found to have difficulties in successfully handle difficult clients as well as their own anxiety before the challenges of the therapeutic Alliance (Bachelor, 2013; Mikulincer et al., 2013). In this study, avoidant attached Alex reported a problem with keeping the limits within the relationship due to his attachment style. The same problem, especially towards female clients, was mentioned by Peter, who had previously classified himself with the same avoidant style. They both relate their tendency to be protective towards themselves and to the others since their childhood with their capacity to provide themselves as overprotective caregivers during therapy, a hypothesis about therapists' ability to connect already mentioned by Bucci et al. (2016). Although boundaries matters were mentioned as constructive issues a therapist should take into account when working with insecure clients (Geller \& Farber, 2015), the issue has not yet discussed in relation to therapists insecure attachment style. Interestingly, both therapists also agreed that criticism and provocation can strongly trigger their self-trust, provoke anger and therefore negatively affect the relationship with the client.

Ambivalent attached Anna and Maria reflected on the way they experience the therapeutic Alliance in the light of their anxious attachment style. Anna appeared really sensitive when she had to deal with early dropouts of her clients, connecting her vulnerability with her deep fear of becoming abandoned. On the other hand she stated that her anxious bond helped her once to better connect with a female with the same attachment style with no further research finding to similarly exist and unlike former research finding that anxious attached therapists are less empathic and caring (Rubino et al., 2000) and therefore able to achieve a lower Alliance quality (Dinger et al., 2009). Maria referred to a number of challenges she has faced while building rapport with clients but she does not link those common challenges exclusively with her own anxious bond and she appears to better reflect research finding that do not link therapist's attachment style with the overall therapeutic Alliance (Ligiero \& Gelso, 2002; Romano et al., 2008; Dinger et al., 2009; Schauenburg et al., 2010) as well as Dinger and Strack's assumptions that a large number of psychotherapists who were classified as insecurely attached during their study were found to build meaningful therapeutic rapport.

\section{Activation while working with clients of different stages of change}

Psychotherapy has been described as a relational exercise between the dyad that aims to bring change for the client (Hoffart \& Hoffard, 2014). For integrative psychotherapists, the purpose of the Therapeutic Relationship is to facilitate an effective change of the dysfunctional behavior of the client through specific stages and levels (Prochaska \& DiClemente, 2005).

That change takes place within the relational environment between therapists and clients while therapists ability to provide a safe environment is catalytic for the process of change (Geller \& Porges, 2014). This question discusses the possible activation of the therapist's attachment style exclusively depending on the client's stage of change rather than on other factors. No previous study exists on this topic so as to compare our finding, thus, only assumptions can be made on the finding of this research.

"Change" can be a really demanding process not only for clients but also for therapists who are operating as change experts and facilitators (Prochaska \& DiClemente, 2005) by taking up different roles at every stage and trying to maintain the dynamic process of the Therapeutic Relationship.

Alex and Peter reported about their experience while working with clients at a different stage of change and their perspectives due to their avoidant Attachment style. They both described the pre-contemplation stage of change as the most challenging one. Alex referred that clients who tend to remain at the stage for a long time can cause great anxiety to him, while Peter's anxiety seems to be triggered by the chaotic situation one can experience during the pre-contemplation stage. Ambivalent attached Anna and Maria also mentioned the initial stages as the most demanding ones. Anna insisted on her fear of abandonment and clients' dropouts that are bound to happen during the early stages while Maria reflected on her nervousness before her clients' unawareness of the real problem. Maria also described her anxiety during the preparation stage and her fear for her suggested interventions to be rejected by her clients, something that she could obviously link with her anxious attachment style. According to DiClemente et al. (1991) at this stage the therapist takes up a caring role, thus an assumption could be that insecurely attached therapists appear less capable in taking on the caregiver's role (Mikulincer et al., 2013). On the other hand, we cannot overlook the fact that initial stages of change are demanding anyway since the Therapeutic Relationship has not been yet formed. Eventually, further focused research is suggested on the topic.

\section{Coping with the activation}

This question discussed the coping strategies each of the four insecure attached participants have used to face the negative effects of the activation of their attachment style during the treatment process. All interviewees agreed with Bowlby (1988) on the importance of therapists' awareness towards their Attachment Style, which was also described by Holmes (2010) as a prerequisite to effective therapists and more recently suggested as substantial for forming strong therapeutic Alliances (Bucci et al., 2016).

Regardless of their insecure type of attachment, they all mentioned the supportive role of supervision. Additionally, to supervision, reflective thinking was applied by Anna, Alex and Peter who agreed on the need for continuous reflection on how they offer themselves to their clients (Bowlby, 1988). Anna found useful to also bring the issue in her personal therapy, a choice that according to research findings can enhance therapist reflective abilities (Rizq \& Target, 2008). Although a later study, always by Rizq and Target (2010), suggested opposite results regarding personal therapy, such as intra personal conflicts and preoccupations towards particular clients no participant of this study mentioned that the awareness of their attachment style can raise their defenses for clients of specific Attachment Styles (Dozier, Cue \& Barnett as cited in Bachelor et al., 2010).

\section{The client's attachment style}

All participants in this study were asked to discuss their experience on the importance of their clients' Attachment Styles for the Therapeutic Relationship and outcome. They all agreed with existing research findings that a client's relational background can be catalytic for the Therapeutic Relationship and the way a therapist is perceived as an attachment figure by the client (Cortina, 2013) and therefore they try to take insights about their clients' attachment style through the assessment process in order to predict possible challenges in the relationship, as suggested by Levy et al. in their study (2011). 


\section{Working with clients of different Attachment Styles}

Participants reflected their experience of working with clients of different Attachment Styles (Appendix 1). As expected, they all reported that securely attached clients have the capacity to positively respond to the Therapeutic Relationship, a view that coincides with the study of Romano et al. (2008) who found securely attached clients to better engage to and collaborate in psychotherapy. Peter described such clients as having a firm sense of the relationship and the therapeutic process. He explained that securely attached clients respond better to therapy and in a relatively shorter time than the insecure ones because they are bound to fewer slips. Sharing the same view, Sofia stressed out the capacity to secure attached clients to attune with the therapist because of their positive relational memories (Bachelor et al., 2010). An interesting finding in this study was that two out of five interviewees stated that they have rarely worked with securely attached clients because according to what they believe individuals with a secure Attachment Style rarely go to therapy. Unlike their experience, Sofia, the only secure attached therapist of this study, shared a totally diverse experience with the majority of their clients being of the secure attachment style. To the researcher's knowledge, no research findings so far comply with the above suggestions.

On the other hand, a number of studies agree with participants reports about their demanding work with insecurely attached clients and the higher challenges expected when working with them (Geller \& Farber, 2015) because of their inability to establish positive rapports (Diener \& Monroe, 2011).

In particular, the attachment system of ambivalent clients can be persistently activated leaving them overwhelmed by negative feelings and anxiety (Kobak \& Seerey as cited in Romano et al., 2008). Anxious attached Anna and Maria recalled a couple of anxious clients and reflected on the transference of their anguish within the Therapeutic Relationship and procedure. Moreover, such clients were described by Alex as getting easily involved in therapy but suffering high anxiety because of their need for high-performance something that complies with existing research findings of Levy et al., who reported anxious attached clients' tendency to easily engage to therapy at first place and even regarded as easy to treat as they cooperate well (Levy et al., 2011). Positive therapeutic outcomes for them, though, are less expected according to another study (Fonagy as cited in Levy et al., 2011). Both Alex and Peter agreed with ambivalent clients' poor outcomes because of their need for quick result and underlined their need to become over depended on the therapist something that can be attributed to their tendency to be over-focused on attracting secure and care from others (Bachelor et al., 2010; Connors, 2011; Marmarosh et al., 2014).

Avoidant clients were described in this study as the most challenging ones especially at the beginning of the relationship. Alex experience that they can be really suspicious during their background interview complies with similar results speaking about avoidant clients' hesitation disclosing themselves and suspicions towards their therapist (Bachelor et al., 2010; Levy et al., 2011). They usually appear unstable during therapy, Alex noted, because of their difficulty in reaching the right decision, consequently, they may cancel their appointments and move them all the time. Peter recalled a similar experience, too. Opposite to anxious attached clients, they do not feel comfortable with intimacy (Connors, 2011) and, thus, they avoid dependency (Marmarosh et al., 2014). Maria and Sofia referred to avoidant clients' difficulty in trusting the therapist, confirming Connors findings that consequently, avoidant clients are less likely to seek for helping relationships, even in hard times (Connors, 2011). While working with clients who demonstrate an avoidant Attachment Style, a therapist might need patience and take up a more engaging role (Levy et al., 2011), because according to Sofia and Anna's experience avoidant clients need more time to connect and are bound to early dropouts. Even they have difficulty to ask for help, and when it is given they tend to withdraw (Bachelor et al., 2010 and Dozier as cited in Levy et al., 2011).

As far as clients who belong to the disorganized attachment style are concerned, they have been characterized as traumatized with high defensive mechanisms and an overwhelming emotional status (Cortina, 2013), which reflects on the Therapeutic Relationship (Pearlman \& Courtois, 2005). Anna, who was the only therapists with experience with such clients, described the way the relationship suffered because of her difficulty to understand the client. All in all, it seems that the experience of the participants coincides with the existing.

\section{Hot combos and the Therapeutic Relationships}

An interesting part of this research that lacks reach research findings, despite the evidence-based suggestion that therapists' Attachment Styles do interact which the attachment style of their clients (Mikulincer et al., 2013), has been participants' narrations about the dynamics or hot-combos created among different Attachment Styles of the therapist and the client.

All participants, even Sofia, who self-referred as having a secure Attachment Style, reflected their experience with specific client Attachment Styles that strongly trigger their own attachment patterns.

Avoidant attached Alex and Peter reflected that they are by far challenging experience of working with also avoidant attached clients; they described the risk of a competitive relationship where empathy is jeopardized by therapist's negative feelings and a positive Therapeutic Relationship seems unable to be set. Research on therapists with avoidant attachment style has reported no similar results before while an older study by Romano et al. (2008) found a lack in depth in the middle sessions relationship between avoidant therapists and anxious clients. According to Black et al., (2005) anxious therapists may have a difficulty to handle challenges in therapy when working with clients of a similar style, something that can negatively affect the relationship. Anxious attached Anna and Maria shared their own common experience describing the risk of becoming overwhelmed by their own anxiety when working with clients of the same anxious Attachment Style. Both therapists, though, would agree with Alex and Peter and finally showed as the hottest combo in their case was their work with avoidant clients as well. With clients showing an avoidant Attachment Style, their difficulty to give trust as well as their tendency to leave therapy were mentioned as the greatest triggering factors for anxious attached therapists' personal trauma of rejection and abandonment. Finally, avoidant clients, because of their trust issues and poor communication during therapy, can even become a challenge for securely attached therapists, according to Sofia's narrations.

\section{The total impact of the Therapist's Attachment Style on the Therapeutic Relationship and outcome}

Insecurely attached participants reflected negative influence such us ruptures and early dropouts, while the securely attached participant echoed a positive impact. Three out of five participants outlined the importance of therapists' awareness towards their attachment patterns as a prerequisite for a solid rapport and suc- 
cessful therapeutic outcomes just as mentioned by Bucci et al. (2016). Education on Attachment Theory which was also suggested by Romano et al. (2008), supervision and personal therapy were suggested for novice therapists by anxious attached Anna, as means of regulation of their insecure Attachment Styles and unlike Dozier, Cue and Barnett findings as cited in Bachelor et al. (2010), who assumed that awareness of their vulnerabilities can strengthen therapists' defenses towards particular clients. Avoidant attached Peter reflected a similar experience to Anna: when becoming aware of their insecurity, insecurely attached therapists can regulate it by trying to act under the principles of secure relationships. For Peter, awareness of his attachment style helped him to better recognize hot combos with his clients and therefore adapt himself properly for the relationship's sake. Only one out of five therapists, the secure attached Sofia, did not agree with Black et al. (2005), who reported better outcomes and stronger Alliances for securely attached therapists. She insisted on the importance of client's Attachment Style. She pointed out that her positive attachment style can operate as a solid basis for the Therapeutic Relationship but it is not always enough to beat the insecure Attachment Styles of her clients, an experience that complies with the aspect that even a therapist's Attachment Style can be activated during therapy, although this may be less likely to impact the relationship than the client's Attachment Style (Black et al.; Dozier et al.; Dunkle \& Friedlander; Mohr, Gelso \& Hill; Rubino et al.; Sauer et al.; as cited in Marmarosh et al., 2014).

\section{Conclusions}

\section{Limitations and strengths}

To start with, the present study is of high relevance to psychotherapy since its subject discusses the therapeutic Alliance and Attachment Theory with both terms as well as their correlation, to play an important role on the therapeutic outcome. Additionally, to the researcher's best knowledge there has been no similar research attempt to investigate therapists' perceptions on the therapeutic Alliance through their own Attachment Styles, whereas the existing relevant literature has been based on quantitative methods and might lack the depth of a therapist's in-session experience. Moreover, this investigation attempt is focused on the detailed descriptions of trainee psychotherapists and in particular on those who work under the Integrative approach. Therefore, it might be of great interest to find out the perceptions on the Attachment of those who integrate Attachment Theory in therapeutic action. Plus, Integrative psychotherapists haven't been investigated under this question so far, even though the Integrative approach has lately gained popularity among therapists. This study is also worthwhile for both trainee therapists and relevant educational curricula. Trainees might find their own concerns among our participants' narrations and therefore enhance their reflections and practice, through the easily understood language employed by of qualitative studies. Trainers and clinical supervisors could be also informed about novice therapist thoughts and feelings regarding their attempt to form positive Alliances and provide themselves as attachment figures, and thus become more effective in their role.

Despite the relevance and importance of this study, a number of limitations and delimitations should be acknowledged in advance. First of all, the aim of this study was an investigation attempt on the perceptions of a rather small sample of trainee psychotherapist on the subject and it can only be seen as such. This means that the finding of this research was not tested for their statistical significance, thus, they cannot be extended to the wider population (Smith \& Osborn, 2008), something that mostly concerns the quantitative analysis. Moreover, this study was applied to trainee psychotherapists and should be regarded that the nature of the sample is to be considered in regard to the outcomes since senior experienced therapists might offer different outcomes. Another limitation that should be taken into account is that participants' responses on their Attachment Styles were self-reported and it is only assumed that participants' evaluations were honest and were formed under common criteria. There was no in advance interview on participants Attachment Style that according to Griffin and Bartholomew (1994) can validate their self-reported attachment.

Furthermore, despite the researcher's efforts to ensure homogeneity of participants, the difference within the sample can be found. For instance, female participants were more than males, while their ages differ significantly. Additionally, recruitment bias should also be considered, since we can assume the interest in the influence of their Attachment Style for those who agreed on taking part in this research.

\section{Implications of the study and further research}

The findings of this exploratory research demonstrated the relevance of Attachment Theory for integrative psychotherapy, as well as the operation of the therapist's Attachment Styles for the development of the therapeutic Alliance. Both theoretical and clinical implications can be suggested relating the outcomes of the study.

\section{Theoretical implications}

All participants in the research agreed on the importance of the Attachment Theory for their clinical practice, something that has received longstanding acknowledgement in so far literature, too. They reported a number of the Theory's applications and reported that they have mainly used it for diagnostic purposes as it seems to provide them with useful information about the Attachment Style of their clients and hence about clients' ability to relate with third parties, as well as, with their therapists. Therapists declared aware of their personal Attachment Styles and agreed on the activation of those styles during treatment, a condition that has already been confirmed by other studies. Therapists with unsafe Attachment Styles talked about problems and reported even termination of treatment because of this activation while the securely attached therapist described positive effects, already assumed and confirmed by some more research, too. On the other hand, the participants did not clearly state whether their insecure bond could be influencing the Therapeutic Relationship and the outcome of the treatment; even the therapist's Attachment Style appeared to be triggered mainly in the initial stages of relationship and client's change, its awareness through constant reflection, training, supervision, and personal therapy seems to have good results on the therapist's ability to regulate it. These findings raised a question about previous research, which has shown that this kind of awareness may lead to an increase in therapists' preoccupation about their ability to work with certain clients. Which way supervision and education can work, in case they can, in managing therapists' Attachment Styles, is an area for which further research could be proposed, since both components are determinant within training protocols for trainee psychotherapists. In addition, another point of particular interest that arose in this research, one that may lead to a deeper understanding of the mechanism of activation of the ther- 
apist's attachment style during therapy, is the way this is triggered by the different Attachment Styles of the clients. This study not only confirmed the already reported importance of client's attachment style for the therapeutic Alliance, but also came with a new suggestion about clients who belong to the avoidant attachment style tend to be the most challenging ones for all therapists' Attachment Styles, even for those with a secure attachment. The hypothesis of hot combos between clients and therapists is in need of further study before solid results can be reached.

\section{Clinical Implications}

Clinical implications from the findings of this study can be also suggested. The first relates to the importance and relevance of the Theory of Attachment for psychotherapy irrespective of a therapist's theoretical orientation (Hill \& Knox, 2009) This study confirmed a variety of implications of Attachment Theory for diagnostic, as well as therapeutic purposes within the integrating psychotherapeutic model while narrative accounts of participants underlined the significant role of the Theory in the therapeutic Alliance (Wallin, 2007). All therapists reported that even they were introduced to Attachment Theory during their Bachelor studies it was not until their specialization placement than they make sense of it and were helped to better understand their clients' relational system though Attachment Theory and therefore facilitate their capacity to connect. This suggests that the Theory of Attachment is useful to be included in all integrating approaches and the way this can be addressed is through clinical training protocols and practice. A second implication was raised through participants' narrations about the enhancement of their professional evolution through the Attachment Theory, which was described as able to foster selfreflectivity and supervision process, foresee and discuss ruptures on the Alliance because of the Attachment Styles of the dyad. Awareness of attachment principles in such cases could be suggested as an imperative opt-in supervisors' demanding training as well.

\section{Conclusions}

This research has provided with interesting findings of the way trainee Integrative psychotherapist experience the therapeutic Alliance in the light of their Attachment Styles. Rich individual narratives of participants' personal experience were provided by the use of Interpretive Phenomenological Analysis and lead to research and clinical suggested implications. Such implication is the need for further qualitative research on the correlation between therapist and client Attachment Styles that can facilitate therapists to understand and regulate their insecure patterns and to strengthen their capacity to build a stronger therapeutic Alliance that lead to better outcomes. Eventually, the benefit of raising therapists' awareness towards their attachment styles through training protocols and supervision can be a clinical implication which targets psychotherapist' professional evolution.

\section{References}

Ackerman, S. \& Hilsenroth, M. (2003). A review of therapist characteristics and techniques positively impacting the therapeutic Alliance. Clinical Psychology Review, 23(1), 1-33.

Ainsworth, M. D. S., Blehar, M. C., Waters, E., \& Wall, S. (1978). Patterns of attachment: A psychological study of the Strange Situation. Hillsdale, NJ: Erlbaum.
Bachelor, A., Meunier, G., Laverdiére, O. \& Gamache, D. (2010). Client attachment to therapist: Relation to client personality and symptomatology, and their contributions to the therapeutic Alliance. Psychotherapy: Theory, Research, Practice, Training, 47(4), 454-468.

Bachelor, A. (2013). Clients' and therapists' views of the therapeutic Alliance: similarities, differences and relationship to therapy outcome. Clinical Psychology and Psychotherapy 20, 118135.

Baldwin, S., Wampold, B. \& Imel, Z. (2007). Untangling the Alliance-outcome correlation: Exploring the relative importance of therapist and patient variability in the Alliance. Journal of Consulting and Clinical Psychology, 75(6), pp.842852.

Bankart, P.C. (1997) Talking cures: A history of western and eastern psychotherapies. California: Pacific Grove.

Bartlett, D. (1998). Stress. Buckingham: Open University Press.

Beutler, L. E., Machado, P. P. P. \& Allstetter Neufeld, S. (1994). Therapist variables. In Bergin, A. A. and Garfield, S. L. (ed). Handbook of Psychotherapy and Behaviour Change. New York: Wiley.

Black, S., Hardy, G., Turpin, G. \& Parry, G. (2005). Self-reported attachment styles and therapeutic orientation of therapists and their relationship with reported general Alliance quality and problems in therapy. Psychology and Psychotherapy: Theory, Research and Practice, 78(3), 363-377.

Bordin, E. (1979). The generalizability of the psychoanalytic concept of the working Alliance. Psychotherapy: Theory, Research and Practice, 16, 252-260.

Bowlby, J. (1977). The making and breaking of affectional bonds. I. Aetiology and psychopathology in the light of attachment theory. An expanded version of the Fiftieth Maudsley Lecture, delivered before the Royal College of Psychiatrists, 19 November 1976. The British Journal of Psychiatry, 130(3), pp.201-210.

Bowlby, J. (1988). A Secure Base (Routledge Classics). London: Routledge.

Britton, P. \& Fuendeling, J. (2005). The Relations Among Varieties of Adult Attachment and the Components of Empathy. The Journal of Social Psychology, 145(5), 519-530.

Bruck, E., Winston, A., Aderholt, S. \& Muran, J. (2006). Predictive Validity of Patient and Therapist Attachment and Introject Styles. American Journal of Psychotherapy, 60(4), 393-406.

Bucci, S., Seymour-Hyde, A., Harris, A. \& Berry, K. (2016). Client and Therapist Attachment Styles and Working Alliance. Clinical Psychology and Psychotherapy, 23(2), 155-165.

Cassidy, J. \& Shaver, P. (2008). Handbook of attachment. London: Guilford Press

Cassidy, J., Jones, D.S., \& Shaver, R.P. (2013). Contributions of Attachment Theory and research: A framework for future research, translation, and policy. Development and Psychopathology, 25, 1415-1434.

Catty, J., Winfield, H. and Clement, S. (2007). The Therapeutic Relationship in secondary mental health care: a conceptual review of measures. Acta Psychiatrica Scandinavica, 116(4), pp.238-252.

Charmaz, K. (2014). Constructing grounded theory. London: Sage.

Clarke, V. \& Braun, V. (2016). Thematic analysis. The Journal of Positive Psychology, 12(3), 297-298.

Collins, L. (2007). Earning a secure attachment style: The therapist as a surrogate attachment figure in the therapeutic dyad. Doctoral dissertation, Auckland University of Technology.

Connors, E.M. (2011). Attachment Theory: A "secure base" for 
psychotherapy integration. Journal of Psychotherapy Integration, 21(3), 348-362.

Cortina, M. (2013). The use of Attachment Theory in the clinical dialogue with patients. Psychodynamic Psychiatry, 4(3), 397418.

Creswell, J. (2007). Qualitative inquiry and research design. Thousand Oaks: Sage.

Daly, K. \& Mallinckrodt, B. (2009). Experienced therapists' approach to psychotherapy for adults with attachment avoidance or attachment anxiety. Journal of Counseling Psychology, $56(4), 549-563$.

Daniel, S. (2006). Adult attachment patterns and individual psychotherapy: A review. Clinical Psychology Review, 26(8), pp.968-984.

Derby.ac.uk. (2018). Research Ethics - Research Ethics and Integrity - University of Derby. Available from: https://www.derby.ac.uk/research/uod/researchethicsandintegrity/researchethics/. Accessed 2 Feb 2019.

DiCicco-Bloom, B. \& Crabtree, B. (2006). The qualitative research interview. Medical Education, 40(4), 314-321.

DiClemente, C., Prochaska, J., Fairhurst, S., Velicer, W., Velasquez, M.M., \& Rossi, J.S. (1991). The process of smoking cessation: An analysis of precontemplation, contemplation, and preparation stages of change. Journal of Consulting and Clinical Psychology, 59(2), 295-304.

Diener, M. \& Monroe, J. (2011). The relationship between adult attachment style and therapeutic Alliance in individual psychotherapy: A meta-analytic review. Psychotherapy, 48(3), 237-248.

Dinger, U., Strack, M., Sachesse, T., \& Schauenburg, H. (2009) Therapists' attachment, patients' interpersonal problems and Alliance development over time in inpatient psychotherapy. Psychotherapy: Theory, Research, Practise, Training, 46(3), 277-209.

Dozier, M., Cue, K. \& Barnett, L. (1994). Clinicians as caregivers: Role of attachment organization in treatment. Journal of Consulting and Clinical Psychology, 62(4), 793-800.

Duncan, B.L., Hubble, A.M., Miller, S.D, \& Wampold, B.C. (2009). The heal and soul of change. Washington D.C: APA.

Dunkle, J. H., \& Friedlander, M. L. (1996). Contribution of therapist experience and personal characteristics to the working Alliance. Journal Of Counselling Psychology, 43(4), 456-460.

Edwards, R. \& Holland, J. (2013). What is qualitative interviewing? Bloomsbury Academic.

Epstein, L.D. (1995). Attachment and psychotherapy: An analogue study. Doctoral dissertation, University of Denver, 1995.

Fassinger, R. (2005). Paradigms, praxis, problems, and promise: Grounded theory in counseling psychology research. Journal of Counseling Psychology, 52(2), 156-166.

Fielding, N. (1993). Qualitative interviewing. in Gilbert N. (ed.) Researching social life. London: Sage; 135-153.

Fisher, J. (2014). Brain to brain: Interpersonal neurobiology and the traumatic transference. CMI Education.

Freud, S. (1958). On the beginning of treatment: Further recommendations on the technique of psychoanalysis. In J. Starchey (ed.). The standard edition of the complete psychological works of Sigmund Freud. London: Hogarth Press.

Geller, D.J., \& Farber, A.B. (2015). Attachment style, representations of psychotherapy, and clinical interventions with insecurely attached clients. Journal of Clinical Psychology, 71(5), 457-468.

Geller, S. \& Greenberg, L. (2002). Therapeutic Presence: Therapists' experience of presence in the psychotherapy encounter / Therapeutische Präsenz: Erfahrungen von Therapeuten mit Präsenz in der psychotherapeutischen Begegnung / La Presencia Terapéutica: La Experiencia de la Presencia que Viven los Terapeutas en el Encuentro Psicoterapéutico. Person-Centered and Experiential Psychotherapies, 1(1-2), 71-86.

Geller, S. \& Porges, S. (2014). Therapeutic presence: Neurophysiological mechanisms mediating feeling safe in Therapeutic Relationships. Journal of Psychotherapy Integration, 24(3), pp.178-192.

Gerhardt, S. (2015). Why love matters. Hove: Routledge

Giannouli, V. (2020). Business ethics in healthcare: The case of Greece. In: Examining Ethics and Intercultural Interactions in International Relations. IGI Global; pp. 138-167.

Giannouli, V., Tegos, T., Zilakaki, M., \& Tsolaki, M. (2019). Elders and mental capacity: Using a qualitative approach to examine views on independence and protection across the Balkans. Hellenic Journal of Nuclear Medicine, 22, 122-139.

Greenson, R. R. (1967). Technique and practice of psychoanalysis. New York: International Universities Press.

Griffin, D., \& Bartholomew, K. (1994). Models of the self and other: Fundamental dimensions underlying measures of adult attachment. Journal of Personality and Social Psychology, $67(3), 430-445$.

Guina, J. (2016). The talking cure of avoidant disorder: Remission through earned-secure attachment. American Journal of Psychotherapy, 70(3), pp. 233-245.

Harris, T. (2004). Implications of Attachment Theory for Working in Psychoanalytic Psychotherapy. International Forum of Psychoanalysis, 13(3), 147-156.

Hatcher, R. \& Barends, A. (2006). How a return to theory could help Alliance research. Psychotherapy: Theory, Research, Practice, Training, 43(3), 292-299.

Haugh, S. \& Paul, S. (2009). The Therapeutic Relationship. Rosson Wye: PCCS Books.

Hill, C. E. \& Knox, S. (2009). Processing the Therapeutic Relationship. Psychotherapy research, 19, 13-29.

Hoffart, A., \& Hoffard, R.A. (2014). Psychotherapy integration through general therapy change principles: Missing the core of psychotherapy? Journal of Psychotherapy Integration. 24(4), 263-274.

Holloway, I. \& Wheeler, S. (1996). Qualitative research for nurses. Oxford: Blackwell Science.

Holmes, J. (2001). The search for the secure base: Attachment Theory and psychotherapy. London: Routledge.

Holmes, J. (2010). Integration in psychoanalytic psychotherapy an attachment metaperspective. Psychoanalytic Psychotherapy, 24, 183-201

Horvath, A. \& Symonds, B. (1991). Relation between working Alliance and outcome in psychotherapy: A meta-analysis. Journal of Counseling Psychology, 38(2), 139-149.

Horvath, A. O., Del Re, A. C., Flückiger, C., \& Symonds, D. (2011). Alliance in individual psychotherapy. Psychotherapy, 48, 9-16.

Imel, E.Z., Hubbard, A.R., Rutter, M.C. \& Simon, G. (2013). Patient-rated Alliance as a measure of therapist performance in two clinical settings. Journal of Consulting and Clinical Psychology, 81(1), 154-165.

Johansson, H. \& Eklund, M. (2003). Patients' opinion on what constitutes good psychiatric care. Scandinavian Journal of Caring Sciences, 17(4), 339-346.

Johnson, M.S., \& Whiffen, E.V. (2003). Attachment processes in couples and family therapy. New York: The Guildford Press. 
Kim, D., Wampold, B. \& Bolt, D. (2006). Therapist effects in psychotherapy: A random-effects modeling of the National Institute of Mental Health Treatment of Depression Collaborative Research Program data. Psychotherapy Research, 16(2), 161-172.

Kirsh, B. \& Tate, E. (2006). Developing a Comprehensive Understanding of the Working Alliance in Community Mental Health. Qualitative Health Research, 16(8), 1054-1074.

Kvale, S. (2007). Doing Interviews. London: Sage.

Langdridge, D. (2007). Phenomenological psychology: Theory, research and method. Essex: Pearson Education Ltd.

Legislation.gov.uk. (2018). Data Protection Act 1998. Available from: http://www.legislation.gov.uk/ukpga/1998/29/introduction. Accessed 2 Feb. 2019.

Levitt, H. (2015). Qualitative psychotherapy research: The journey so far and future directions. Psychotherapy, 52(1), 31-37.

Levy, K.N., Ellison, W.D., Scott, L.N., \& Bernecker, S.L. (2011). Attachment Style. Journal of Clinical Psychology, 67(2), 193203.

Ligiero, D. P., \& Gelso, C. J. (2002). Countertransference, attachment, and the working Alliance: The therapist's contribution. Psychotherapy: Theory, Research, Practise, Training, 39(1), 311.

Lilliengren, P., Sandell, R., Falkenstrom, F., Mothlander, R.P., \& Werbart, A. (2015). Secure attachment to therapist, Alliance, and outcome in psychoanalytic psychotherapy with young adults. Journal of Counseling Psychology, 62(1), 1-13.

Main, M., \& Solomon, J. (1990). Procedures for identifying infants asdisorganized/disoriented during the Ainsworth Strange Situation. In: Greenberg M.T., Cicchetti D., \& Cummings M. (ed.). Attachment in the preschool years: Theory, research, and intervention. Chicago, IL: University of Chicago Press; pp. $121-160$

Main, M., Kaplan, N. and Cassidy, J. (1985). Security in Infancy, Childhood, and Adulthood: A Move to the Level of Representation. Monographs of the Society for Research in Child Development, 50(1/2), p.66.

Mallinckrodt, B. (2010). The psychotherapy relationship as attachment: Evidence and implications .Journal of Social and Personal Relationships, 27(2), 262-270.

Mallinckrodt, B., Daly, K., \& Wang, C. D. (2008). An attachment approach to adult psychotherapy. In J. Obegi (ed), Attachment Theory and Research in Clinical Work with Adults. New York: Guilford Press.

Marmarosh, C. L. (2015). Emphasizing the complexity of the relationship: The next decade of attachment-based psychotherapy research: Psychotherapy, 52(1), 12-18.

Marmarosh, L.C., Kivlighan, M.D., Bieri, K., Schutt, J.M.L., Barone, C., \& Choi, J. (2014). The insecure psychotherapy base: Using client and therapist Attachment Styles to understand the early Alliance. Psychotherapy, 51(3), 404-412

Martin, DJ., Garske, J.P., \& Davis, K. (2000). Relation of the therapeutic Alliance with outcome and other variables: A metaanalytic review. Journal of Consulting and Clinical Psychology, 68(2), 438-450.

McCluskey, U. (2005) To Be Met as a Person The Dynamics of Attachment in professional Encounters. London, Karnac: Books.

McLeod, J. (2003). Doing counselling research. London: Sage.

Mikulincer, M., \& Shaver, P. R. (2007). Attachment in adulthood: Structure, dynamics, and change. New York, NY: Guilford Press.

Mikulincer, M., Shaver, R.P., \& Berant, E. (2013). An attachment perspective on therapeutic processes and outcomes. Journal of Personality, 81(6), 606-616.

Mohr, J.J., Gelso, C.J., \& Hill, C.E. (2005).Client and counselor trainee attachment as predictors of session evaluation and countertransference behavior in first counseling sessions. Journal of Counseling Psychology, 52, 298-309.

Morrow, S.L. (2007). Qualitative research in counselling psychology: Conceptual foundations. The Counseling Psychologist, $35,209-235$

Myers, S. (2018). Reflections on Reflecting: How self-awareness promotes personal growth | ADPCA. Adpca.org. Available from: http://adpca.org/journal/reflectionsreflecting-how-selfawareness-promotes-personal-growth. Accessed 2 Aug 2018.

Obegi, J. H. (2008). Attachment Theory and Research in Clinical Work with Adults. New York: Guilford Press.

Orlinsky, D. E., Ronnestad, M. H., \& Willutski, U. (2004). Fifty years of psychotherapy process-outcome research: Continuity and change. In Lambert M. J. (ed.) Handbook of psychotherapy and behaviour change, 5th ed. New York: John Wiley and Sons.

Parish, M. (1999). The nature of the patient's tie to the therapist. Doctoral dissertation, Adelphi University, 1999.

Parish, M., \& Eagle, M. N. (2003). Attachment to the Therapist. Psychoanalytic Psychology, 20(2), 271-286.

Pearlman, A.L., \& Courtois, A.C. (2005). Clinical application of the attachment framework: Relational treatment of complex trauma. Journal of Traumatic Stress, 18(5), 449-459.

Pietkiewicz, I. \& Smith, J.A. (2014) .A practical guide to using Interpretative Phenomenological Analysis in Qualitative Research Psychology. Psychological Journal, 20(1), 7-14.

Ponterotto, J. G. (2005). Qualitative research training in counseling psychology: A survey of directors of training. Teaching of Psychology, 32, $60-62$.

Prochaska, J. O. \& DiClemente, C. C. (2005). 'The transtheoretical approach', in Norcross J. C. and Goldfried M. R. (ed.) Handbook of Psychotherapy Integration (2nd ed), New York: Oxford; pp. 147-171.

Purnell, C. (2010). Childhood trauma and adult attachment. Healthcare Counselling and Psychotherapy Journal, 10, 1-7.

Richardson, J.T.E. (1996). Handbook of Qualitative Research Methods for Psychology and the Social Sciences. Leicester: PBS Books.

Rizq, R. \& Target, M. (2008). 'The power of being seen': an interpretative phenomenological analysis of how experienced counselling psychologists describe the meaning and significance of personal therapy in clinical practice. British Journal of Guidance and Counselling, 36, 131-153.

Rizq, R. \& Target, M. (2010). 'If that's what I need, it could be what someone else needs.' Exploring the role of attachment and reflective function in counselling psychologists' accounts of how they use personal therapy in clinical practice: a mixed methods study, British Journal of Guidance and Counselling, $38,459-481$.

Rogers, C. (1957). The necessary and sufficient conditions of therapeutic personality change. Journal of Consulting Psychology, 21, 95-103.

Romano, V., Fitzpatrick, M., \& Janzen, .J. (2008). The secure-base hyphothesis: Global attachment, attachment to counselor and session exploration in psychotherapy. Journal of Counselling Psychology, 55(4), 495-504.

Ross, R.L. (2006). Talking theory, talking therapy: Emmy Gut and John Bowlby. Issues in Mental Health Nursing, 27, 475-497.

Rubino, G., Barker, C., Roth, T., \& Fearon, P. (2000). Therapist 
empathy and depth of interpretation in response to potential Alliance ruptures: The role of therapist and patient attachment Psychotherapy Research 579 styles. Psychotherapy Research, 10, 408-420.

Sandelowski, M. (1994). Focus on qualitative methods. The use of quotes in qualitative research. Research in Nursing and Health, 17(6), 479-482.

Sauer, E. M., Lopez, F. G., and Gormley, B. (2003). Respective contributions of therapist and client adult attachment orientations to the development of the early working Alliance: A preliminary growth modeling study. Psychotherapy Research, 13, 371-382.

Schauenburg, H., Bucheim, A., Beckh, K., Nolte, t., Brenk, K., Leichesenring., Strack, M., \& Dinger, U. (2010). The influence of psychodynamically oriented therapists" attachment representations on outcome and Alliance in inpatient psychotherapy. Psychotherapy Research, 20, 193-202.

Smith, A. E. M., Msetfi, R. M., and Golding, L. (2010). Adult attachment patterns and the therapeutic Alliance: A systematic review. Clinical Psychology Review, 30, 326-337

Smith, J. A. (1996). Beyond the divide between cognition and discourse: using interpretative phenomenological analysis in health psychology. Psychology and Health, 11, 261-271.

Smith, J. A. (2003). Qualitative psychology - a practical guide to research methods. London: SAGE Publications.

Smith, J. A. (2004). Reflecting on the development of interpretative phenomenological analysis and its contribution to qualitative research in psychology. Qualitative Research in Psychology, 1, 39-54.

Smith, J. A., Flowers, P., \& Larkin, M. (2009). Interpretative Phenomenological Analysis: Theory, Method and Research.
London: Sage

Smith, J., \& Osborn, M. (2003). Interpretative Phenomenological Analysis. In Smith J. (ed.) Qualitative Psychology: A practical guide to research methods. London: Sage.

Smith, J.A., \& Osborn, M. (2008). Interpretative phenomenological analysis. In Smith J.A. (ed.) Qualitative Psychology: A Practical Guide to Methods (2nd ed.). London: Sage.

Smith, J.A., Flowers, P. \& Larkin, M. (2009). Interpretative phenomenological analysis: Theory, method and research. London: Sage Publications Ltd.

Sroufe, A. \& Siegel, D. (2011). The Verdict Is In. Psychotherapynetworker.org. Available from: https://www.psychotherapynetworker.org/magazine/article/97 8/the-verdict-is-in. Accessed 10 December 2019.

Stiles, W., Barkham, M., Twigg, E., Mellor-Clark, J. \& Cooper, M. (2006). Effectiveness of cognitive-behavioural, person-centred and psychodynamic therapies as practised in UK National Health Service settings. Psychological Medicine, 36(4), 555566.

Strauss, A., \& Corbin, J. (1998). Basics of qualitative research: Techniques and procedures for developing grounded theory. Thousand Oaks, CA: Sage.

Taylor, J.P., Rietzschel, J., Danquah, A., \& Berry, K. (2015). The role of attachment style, attachment to therapist, and working Alliance in response to psychological therapy. Psychology and Psychotherapy: Theory, Research and Practice, 88, 240-253.

Wallin, J.D. (2015). Attachment and psychotherapy. New York: The Guilford Press.

Zetzel, E. R. (1956). Current concepts of transference. International Journal of Psychoanalysis, 37, 369-376. 